\title{
Three-Dimensional Computer Simulation as an Important Competence Based Aspect of a Modern Mining Professional
}

\author{
Olesya Aksenova ${ }^{1 *}$, and Anna Pachkina ${ }^{1}$ \\ ${ }^{1}$ T.F. Gorbachev Kuzbass State Technical University, 650000, Vesennyaya 28 st., Kemerovo, Russian
}

\begin{abstract}
The article deals with the problem of necessity of educational process transformation to meet the requirements of modern miming industry; cooperative developing of new educational programs and implementation of educational process taking into account modern manufacturability. The paper proves the idea of introduction into mining professionals learning process studying of three-dimensional models of surface technological complex, ore reserves and underground digging complex as well as creating these models in different graphic editors and working with the information analysis model obtained on the basis of these three-dimensional models. The technological process of manless coal mining at the premises of the mine Polysaevskaya controlled by the information analysis models built on the basis of three-dimensional models of individual objects and technological process as a whole, and at the same time requiring the staff able to use the programs of three-dimensional positioning in the miners and equipment global frame of reference is covered.
\end{abstract}

\section{Introduction}

Nowadays progressive development of mining industry demands highly qualified professionals. It involves the necessity of adaptation of modern educational institutions to meet the requirements of educational services customer as well as of rapid and timely educational process transformation to achieve the qualitative system of analysis and control of the education programs efficiency.

With regard to timely prediction and taking into account the country's changing economic conditions requirements, the mining industry is aimed at the effective and profitable extraction and processing of solid mineral deposits which is to guarantee the underground operation safety and to save people's lives.

Field experience in many branches of industry, successful practices in computerization of work processes and potentialities of three-dimensional computer simulation facilities and of information technologies in general demonstrate the timeliness and urgency of cooperative developing of new educational programs and implementation of educational process taking into account modern manufacturability [1-3].

\footnotetext{
*Corresponding author: olesya_aksenova@mail.ru
} 


\section{Materials and methods}

To create a modern mining enterprise it is necessary to have a completely new approach to the training of professionals. Working out educational programs one should take into consideration the study of three-dimensional models of surface technological complex, ore reserves and underground digging complex as well as creating these models in different graphic editors and working with the information analysis model or system obtained on the basis of these three-dimensional models [4-6].

Information analysis system enables, being based on the online data, to assist in making tactical, strategic and operative management decisions at the enterprise following on from immediate graphic representation of all the necessary data set to the users responsible for the work analysis. Information model as a constituent of information analysis system is an object model given in the form of information describing relevant for this model characteristics and variables of an object along with their connections, object inputs and outputs and allowing with the help of transmitting to the model information about input values changes to simulate possible states of an object; it is total information characterizing essential features and states of an object, process, phenomenon as well as interrelation with the outside. Information analysis system enables to find insights and implicit tendencies, to carry out end-to-end analysis of process steps, actual oncoming of critical developments and abnormal situations, to keep, cumulate and make use of implicit tendencies [7-12].

Information analysis system in operation and development of information analysis models on the basis of three-dimensional models of production facilities are used in the work of mine Polysaevskaya (SIBENCO) in Kemerovo region. Here, for the first time in Russia, the face enabling to carry out manless coal mining was put into operation. The system of manless coal mining is based on cooperative development of three companies specialists: OAO SIBENCO-Kuzbass, MARCO (Germany) and EICKHOFF (Germany).

The purpose of development and implementation of technological coal mining process which is realized and controlled by the use of information analysis models is to increase the enterprise profits, to enhance underground operations safety and to save people's lives.

The methods used to achieve the purpose are to control and timely make a decision in case of emergency, to increase employees work efficiency thanks to highly-professionally trained university graduates.

\section{Results and Discussion}

Manless coal mining involves coal winning technology without people's presence in a stoping face which solves not only technological but also the most important social and ecological problems - that is to take people out of the face and to release them from heavy manual operations. There are different ways of manless coal mining, each having its own advantages and disadvantages (fig.1). At present the most widely used is the timberless coal winning technology with the help of the following equipment: augers, scraper boxes, sawing machines, equipment system KMD-72, hole blasting, etc. [1, 2, 7].

The three-dimensional scale diagram - mine network at a producing mine forms a complex topological structure (fig. 2). The technological process and equipment control is performed by one operator. This came true thanks to the use of numerous information analysis detectors put on the equipment and integrated system of video monitoring.

For visualization of automatically controlled coal mining technological process threedimensional models of mine openings, extraction and loading equipment, conveyers, transport etc. were made in different graphic editors and afterwards served as a basis for information models.

The given information models and computer performance analysis are able in a 
completely automated mode to monitor operation facilities at any stage of coal mining technological process, to determine and realize the most effective combines movement, damper valves of powered support units, the work of winning-and-transport equipment (fig. 3).

Information system has a dynamic object data structure with an unlimited opportunity to increase functionality. This database in the system serves as an integrating basis of all the system operation modules corporate work. The most significant criteria of liveness and effectiveness of a corporate system are its in-built opportunities for information model development by the users themselves. Indeed, operating personnel of a mining enterprise works, as a rule, with real objects. The engineering technicians duties of chief surveyor's, geologist manager's, production manager's and other services are difficult to formalize and are changing all the time so there is always an opportunity to "misunderstand the task" and so-called "indispensable" professional can change the place of work.

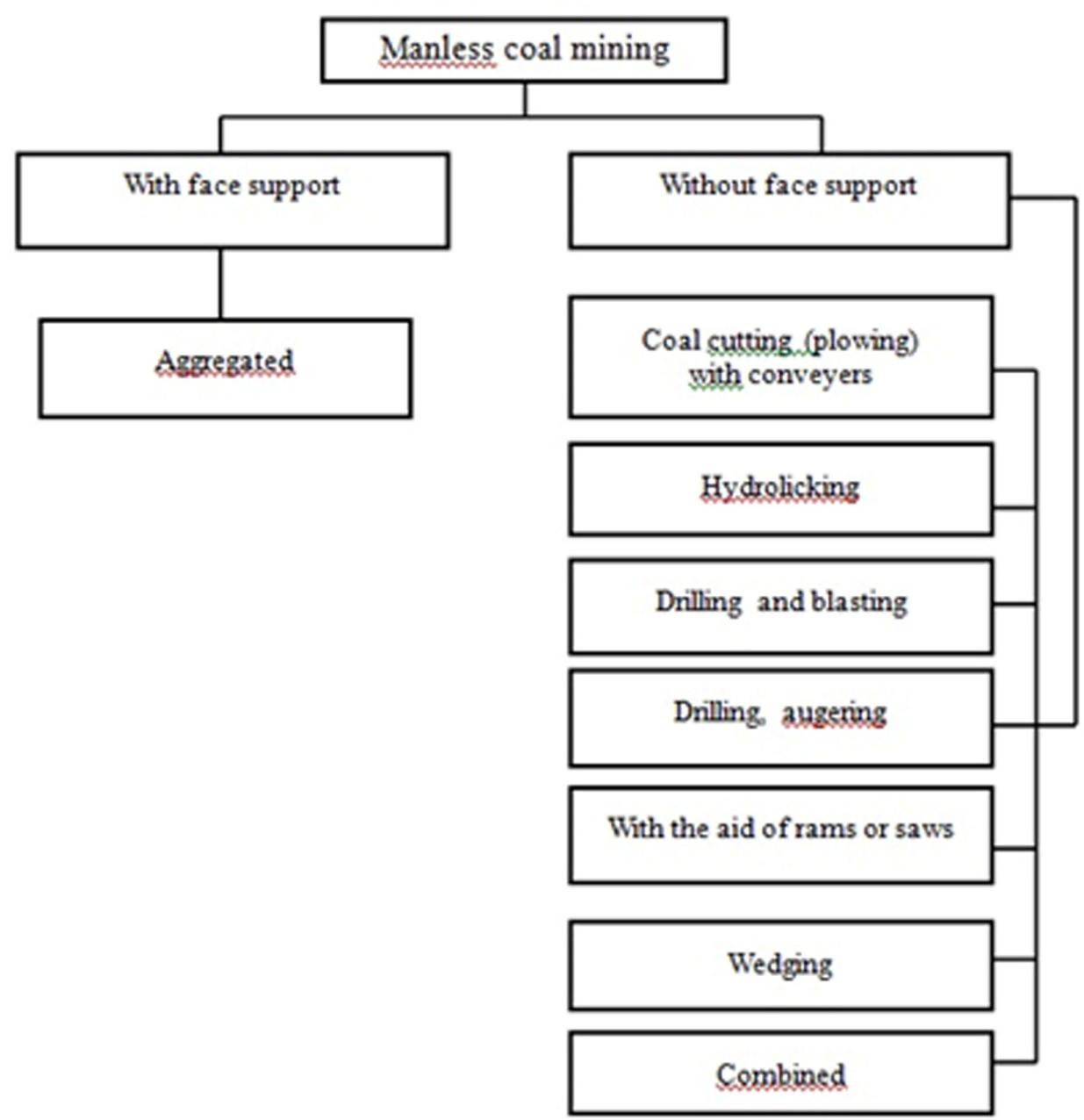

Fig. 1. Classification by the way of manless coal mining. 


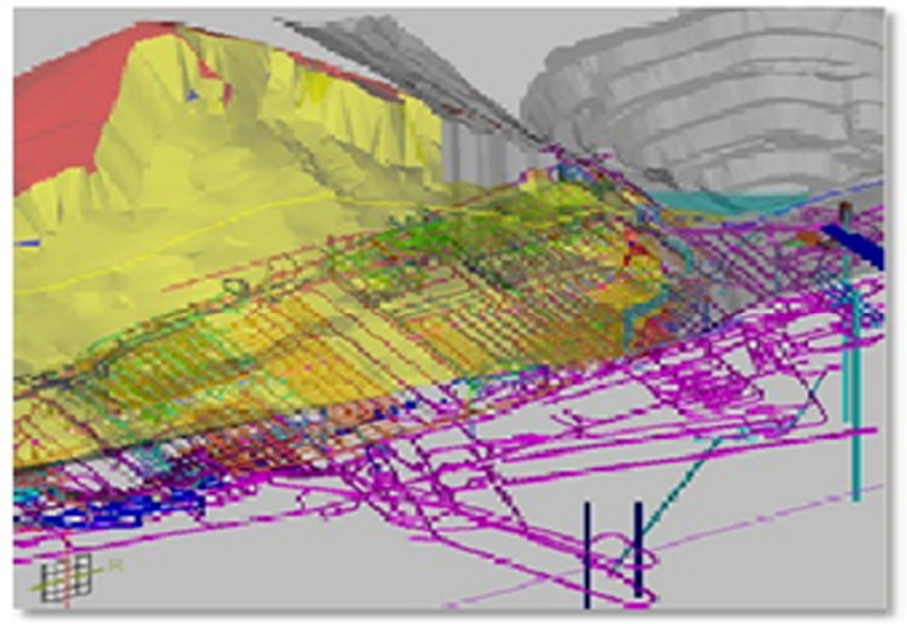

Fig. 2. Three-dimensional system of mine openings.
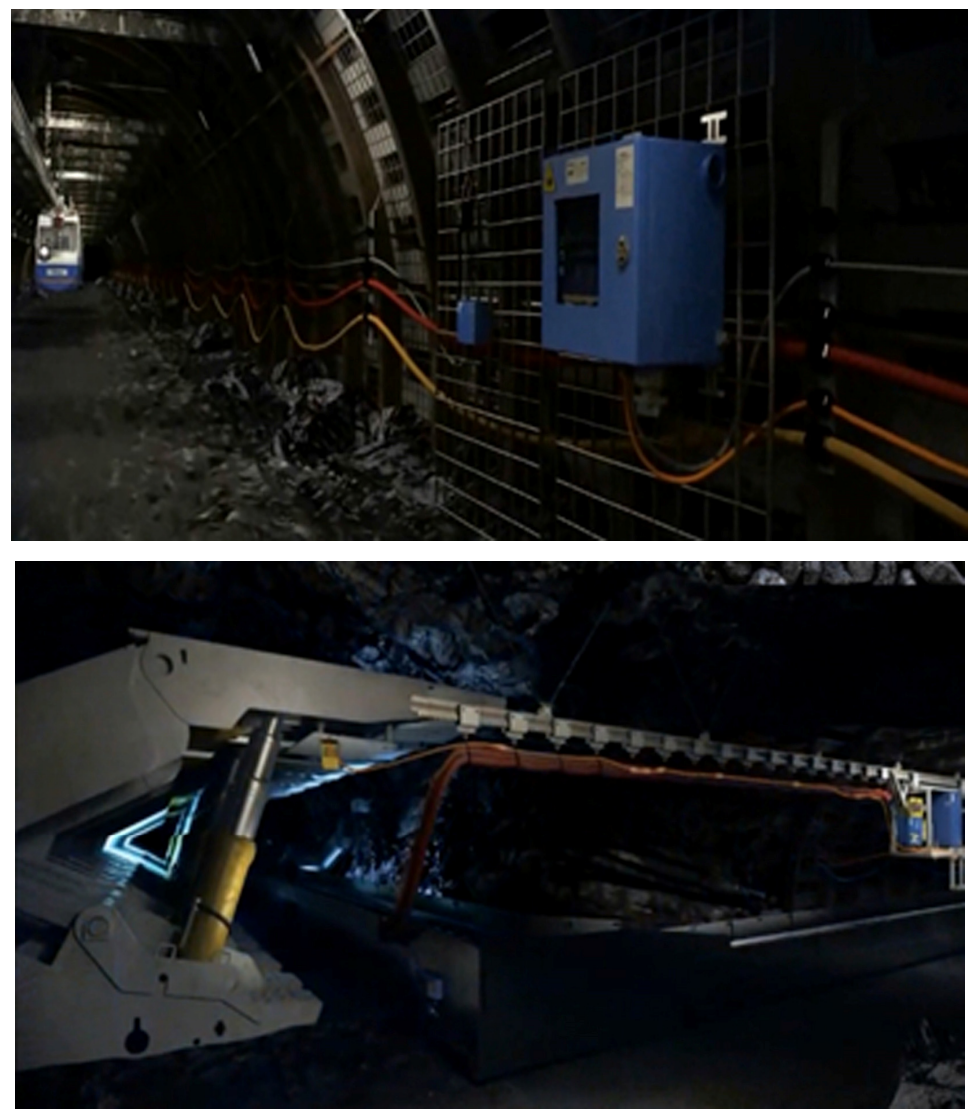

Fig. 3. Information models of individual stages of coal mining technological process.

\section{Conclusions}

Technical solution based on modern information systems should provide: 
1. Interactive visualization of production processes on the basis of 3D model of technological surface complex and underground mine facilities including dynamic lava changes.

2. Calculation and estimation of key enterprise management aspects: profit, output and mineral resources.

3. End-to-end operation control.

That is the reason why there is a necessity for a very flexible, powerful but at the same time user-available tool for self-study and development of data storage structure needed, getting answers to the unknown in advance requests in the informational space. On the other hand, there appears a demand in highly qualified personnel having not only deep theoretical knowledge in the coal mining field but also having a command of three-dimensional computer simulation language both of individual objects and of technological processes on the whole.

So, the development and the implementation of integrated control systems at the coal mining enterprises requires the alteration of the education and reeducation programs for engineering technicians, assistant mine rescue crews and stope miners, introduction into the course of learning the programs of three-dimensional positioning in the miners and equipment global frame of reference.

Implementation of information analysis models complex management systems studying into the educational programs of mining professionals will help to enhance underground operations safety and to save people's lives.

\section{References}

1. A.A. Khoreshok, S.A. Zhironkin, M.A. Tyulenev, M.C. Hellmer, S.V. Potyagailov, IOP Conference Series: Materials Science and Engineering, 142:1, 012122. (2016)

2. D.V. Alekseev, G.A. Kazunina, A.V. Cherednichenko, Journal of Mining Science, 51:5, 917 (2015)

3. S.P. Bakhaeva, V.A. Gogolin, I.A. Ermakova, Journal of Mining Science, 52:3, 454 (2016)

4. M.A. Tyulenev, S.A. Zhironkin, E.A. Garina, International Journal of Mining and Mineral Engineering, 7:4, 363 (2016)

5. T. Gvozdkova, M. Tyulenev, S. Zhironkin, V.A. Trifonov, Yu.M. Osipov, IOP Conference Series: Earth and Environmental Science, 50:1, 012010 (2017)

6. M.A. Tyulenev, T.N. Gvozdkova, S.A. Zhironkin, E.A. Garina, Geotechnical and Geological Engineering, 35:1, 203 (2017)

7. J. Kretschmann, A.B. Efremenkov, A.A. Khoreshok, IOP Conference Series: Earth and Environmental Science, 50:1, 012024 (2017)

8. M. Behandish, T. Horea Ilieş, Computer-Aided Design, 70, 100 (2016)

9. Ba Wenlan, Ren Ning, Cao Lixin, Graphical Models, 82, 1 (2015)

10. Yang Hao, Zhang Hui, Computers \& Graphics, 65, 45 (2017)

11. M. Behandish, T. Horea Ilieş, Computer-Aided Design, 70, 100 (2016) 
